\title{
A Teoria da Ponderação de Princípios na Encruzilhada do Decisionismo Judicial: limita-me ou te devoro!
}

\author{
The Weight of Principles Theory on the Crossroads of the Judicial \\ Decisionism: limit me or i'll devore you!
}

\author{
José Sérgio da Silva Cristóvam \\ Universidade Federal de Santa Catarina, Florianópolis - SC, Brasil
}

\begin{abstract}
Resumo: O artigo aborda a teoria da ponderação de princípios, com base nos contornos traçados pelo neoconstitucionalismo. O modelo ponderacionista tem sofrido críticas sólidas e abalizadas, na medida em que submete o discurso judicial a um profundo deficit de legitimidade e de racionalidade, abrindo caminho para uma clara usurpação da autoridade legislativa por um modelo teórico que permite o império do decisionismo subjetivo e do moralismo judicial. Isso conduz à necessidade de se estabelecerem limites procedimentais e materiais capazes de assegurar a racional aplicação do sistema, essencial fator de legitimação e justificação das decisões sobre conflitos entre princípios e interesses.
\end{abstract}

Palavras-chave: Neoconstitucionalismo. Teoria da Ponderação de Princípios. Decisionismo Judicial.

\begin{abstract}
The article adresses the weight of principles theory, according to the contours drawn by the neoconstitutionalism. The weight of principles model has been suffering from solid and emphatic criticisms, since it submits the judicial discourse to a deep deficit of rationality and legitimacy, opening the way to a clear usurpation of the legislative authority by a theoretical model that allows the empire of subjective decisionism and judicial moralism. This leads to the need of establishing material and procedimental limits that are capable to ensure a rational application the system, wich is essential to legitimate and justify the decisions about the conflift of principles and interests.
\end{abstract}

Keywords: Neoconstitutionalism. Weight of principles theory. Judicial decisionism.

Recebido em: 01/04/2016

Revisado em: 21/02/2017

Aprovado em: 01/03/2017 


\section{Introdução}

O discurso constitucional contemporâneo e a cultura jurídica têm experimentado uma acentuada reformulação nas suas bases teóricas, inclusive com sua interação aos diversos fatores que compõem a sociedade atual. A difusão das teorias do chamado neoconstitucionalismo ${ }^{1}$, com a proposta de superação de algumas das principais teses do positivismo jurídico, tem refletido viva e fecundamente na consolidação de uma renovada teoria da Constituição, pautada pela supremacia da ordem constitucional, a centralidade personalista da dignidade humana, a força normativa dos princípios constitucionais e a eficácia dos direitos fundamentais.

A consolidação da qualidade normativa dos princípios jurídicos reveste-se de considerável relevância, sobretudo no contexto de uma teoria da ponderação de interesses, com a construção de uma nova hermenêutica constitucional, vivificada pelo raciocínio tópico-retórico e pela aplicação da proporcionalidade ${ }^{2}$. No modelo pós-positivista de discurso jurídico, a teoria da ponderação de princípios (e interesses) passou a assumir uma posição de alargada proeminência, povoando quase que por completo o debate jurídico, com destaque para o cenário judicial.

O Estado constitucional de direito vem marcado por alguns traços fundamentais, do que resulta uma estrutura aberta e maleável de princípios constitucionais, no mais das vezes veiculadores daqueles direitos fundamentais conformadores da ordem normativa, por vezes submetidos a relações de conflito ou contraposição, quando da aplicação a determinada situação concreta. Assim, sempre que as ordens constitucional e infraconstitucional (se com aquela compatível) não estabelecerem, de modo abstrato e apriorístico, os juízos ponderativos de prevalência de determinado direito

\footnotetext{
${ }^{1} \mathrm{Na}$ América Latina, inclusive com elevado destaque no Brasil, a ampla difusão das teorias do neoconstitucionalismo ocorreu a partir da sucessiva publicação (em 2003 e 2007) de duas coletâneas de artigos, com as reflexões de renomados autores italianos, espanhóis e latino-americanos, organizadas pelo jurista mexicano Miguel Carbonell (2007) e Sarmento (2009, p. 113-146).

${ }^{2}$ Ultrapassa os limites desse ensaio a análise mais aprofundada sobre a teoria da proporcionalidade. Nesse sentido, consultar: Braga (2009, p. 91-148) e Cristóvam (2016, p. 227-242).
} 
ou interesse (público, coletivo, social, privado, individual), situação assaz comum em um sistema constitucional aberto de regras e princípios como o brasileiro, remanesce a incumbência/atribuição ponderativa conferida em especial ao Poder Judiciário, quando chamado a decidir pela prevalência concreta e relativa de determinado direito ou interesse, segundo as respectivas circunstâncias fáticas e jurídicas, sempre visando à máxima satisfação daquelas vontades normativas preestabelecidas.

Aqui não se está a defender, de forma alguma, uma proposta simplista de chancela a um modelo de decisionismo judicial. Muito pelo contrário, a ponderação judicial deve estar plenamente vinculada à supremacia da Constituição e à prevalência dos direitos fundamentais. Estes são o norte e o limite finalístico da teoria ponderacionista, a gravitar em torno da plena satisfação do sistema constitucional e das normas infraconstitucionais que o complementam e especificam, a partir da concretização daquela sua extensa constelação normativa de regras e princípios legitimamente reconhecidos. Eis, portanto, a problemática central do debate aqui empreendido. $\mathrm{O}$ método de abordagem empregado é o dedutivo, pela técnica de pesquisa bibliográfica, com o levantamento de dados buscando uma análise qualitativa e teórica a respeito do tema investigado.

Não se pode negar, por outro lado, que esses limites não são assim tão racionalmente rígidos, nem em tudo politicamente estáveis e juridicamente infalíveis. De fato, estabilidade política e infalibilidade jurídica não são traços qualitativos comuns a uma ordem democrática inclusiva, aberta e multifária como a brasileira, mas sim a regimes fechados tendentes ao autoritarismo ou até ao totalitarismo.

\section{A Ponderação de Princípios na Encruzilhada do Decisionismo Judicial: a teoria ponderacionista aos pés da Esfinge}

A consolidação da teoria da ponderação de direitos e de interesses permite a construção de um peculiar modelo de Estado de ponderação, ${ }^{3}$ como projeto constitucional dinâmico, aberto e pluralista. Mas, não se

\footnotetext{
${ }^{3}$ A referência ao chamado Estado de ponderação (Abwägungsstaat) quer indicar que, no Estado democrático de direito, a ponderação proporcional assume a condição de medida
} 
pode admitir que do paradigma ponderacionista resulte um insuprimível espaço de incertezas jurídico-políticas, de diuturna e casuística relativização de direitos, com a progressiva corrosão das noções de legalidade e segurança jurídica e o consequente deficit de estabilidade social, política e econômica da comunidade.

Como uma autêntica "Esfinge pós-moderna", o modelo ponderacionista não pode ficar, caso a caso, a desafiar (devorar) os padrões mínimos de racionalidade e segurança do sistema jurídico-judicial, permitindo ao julgador verdadeira usurpação da autoridade legislativa constitucional e infraconstitucional, por meio de obscuras e iletradas ginásticas hermenêuticas, que muito mais procuram encobrir razões subjetivas (moralismo judicial) do que apresentar efetivas justificações jurídicas racionais. Aqui reside a encruzilhada de deslegitimação da teoria da ponderação de princípios, que flerta de forma cada vez mais perigosa, desavisada e recorrente com padrões moralistas de decisionismo judicial, o que reclama a consolidação de limites formais e materiais essenciais à manutenção da pretensão de racionalidade e segurança do discurso jurídico-judicial.

Com efeito, o chamado Estado de ponderação não pode ser convertido em um Reino do "tudo depende", na relativização dos conceitos e institutos jurídicos, que fundam as regras e princípios constitutivos da ordem jurídica vigente. Não se deve abrir espaços para práticas decisionistas dos poderes constituídos, em especial para a subjetividade da atividade judicial. A construção do paradigma da ponderação proporcional deve estar fundada em um método racional de ponderação de interesses, no sentido de assegurar a prevalência relativa daqueles direitos ou interesses marcados pelas respectivas condições de precedência, mas somente para aqueles casos de efetivo conflito entre direitos ou interesses que não disponham de uma justa e adequada solução ponderativa preestabelecida pela ordem normativa, sob pena de clara usurpação jurisdicional da autoridade legislativa.

Interessante ilustrar que, em suas reflexões mais recentes, o próprio jusfilósofo Luigi Ferrajoli, um dos importantes críticos do ponderacionis-

otimizadora dos princípios, bens e interesses albergados pela ordem normativa vigente. Nesse sentido, consultar: Binenbojm (2008, p. 104-108). 
mo principialista e maior expoente da teoria do garantismo jurídico, ${ }^{4}$ não desconsidera os inegáveis espaços de discricionariedade da jurisdição e a importância da teoria da argumentação jurídica, como instrumento de limitação voltado à "fundação da racionalidade do exercício discricional do Poder Judiciário". Inclusive, o jurista italiano reconhece textualmente não haver sentido em "negar ou desconsiderar o papel da ponderação e, de maneira mais ampla, da argumentação na atividade de produção normativa", fazendo referência tanto à "ponderação legislativa, que é fisiológica na esfera das decisões políticas, desde que não estejam em contraste - por comissão e por omissão - com as normas constitucionais", como para a questão da

[...] ponderação judicial nos espaços, igualmente fisiológicos, da interpretação jurídica, que certamente são mais amplos e indeterminados quando as normas não têm a forma de regras, mas, sim, a de princípios. (FERRAJOLI, 2012, p. 46)

Na verdade, a sólida e difundida crítica de Ferrajoli à teoria ponderacionista não é endereçada "ao papel da ponderação na atividade de produção do direito", mas sim "à excessiva ampliação deste papel na atuação legislativa e na interpretação jurisdicional das normas constitucionais”, ou seja, "à excessiva dimensão empírica associada à noção de ponderação". Ao denunciar esse excessivo e indiscriminado recurso à teoria da ponderação, o autor ressalta que o ponderacionismo

[...] terminou se transformando, nestes últimos anos, em uma espécie de bolha terminológica, tão dilatada que chegou às formas mais variadas de esvaziamento e de inaplicação das normas constitucionais, tanto no nível legislativo quanto no nível jurisdicional. (FERRAJOLI, 2012, p. 47)

Infelizmente, a prática decisionista dos tribunais tem oferecido um recorrente festival de exemplos de usurpação judicial da autoridade legis-

\footnotetext{
${ }^{4}$ Ainda que de inegável influência no discurso jurídico contemporâneo, ultrapassam os limites do presente estudo a análise da teoria do garantismo jurídico. Para um estudo aprofundado sobre o tema, consultar: Carbonell e Salazar (2005) e Ferrajoli (2006).
} 
lativa constitucional e infraconstitucional. Sem a menor preocupação com a justificação racional (argumentação jurídica), regras constitucionais e infraconstitucionais são relativizadas e afastadas, com base em discursos rasos e descontextualizados de defesa de "princípios de ocasião", chamados às pressas para salvar decisões apriorísticas e subjetivas.

Uma trágica e verdadeira "principiorragia” que faz jorrar princípios a funcionar como genuínas chaves-mestras que abrem todas as portas (fundamentam decisões de todos os matizes), invadindo o discurso judicial sem a menor preocupação teórica e de argumentação racional. Parâmetros como a razoabilidade e a proporcionalidade viram "mantras de justificação" para toda e qualquer subjetivismo judicial. Como que por um passe de mágica surgem novos princípios, obscuramente drenados de uma Constituição que cada vez mais é aquilo que os tribunais dizem ser e não o resultado da vontade normatizada do legislador constituinte. Não que o Poder Judiciário não seja legítimo intérprete da ordem constitucional, mas isso não o autoriza a funcionar como constante e onisciente legislador constituinte positivo.

Nesse carnaval de inconsistências e instabilidades, a prática dos tribunais não está imune a críticas. Conforme abalizada denúncia de Lenio Luiz Streck (2012), vive-se sob o signo do que ele chama de "pan-principiologismo", uma espécie de "estado de natureza hermenêutico" que traz consigo a abertura para modelos de decisionismo judicial, a partir de uma noção descomprometida e pouco ilustrada da teoria da ponderação. A prática dos tribunais reflete quase um autêntico e preocupante "Leito de Procusto" hermenêutico: se a norma a aplicar diz mais do que se quer, o intérprete corta-lhe um pedaço; se diz menos, estica o seu sentido até alcançar a "medida correta".

Na mesma linha, Carlos Ari Sundfeld chega a fazer referência aos "princípios como armas de espertos e de preguiçosos", ante a comodidade que oferecem aos litigantes espertos, na medida em que ocultam a fragilidade argumentativa de direitos invocados com base em princípios ocos de expressão normativa para determinados casos. Comodidade estendida aos julgadores preguiçosos, que usam "[...] fundamentos fáceis para esconder a superficialidade de sua decisão” (SUNDFELD, 2012, p. 70). 
As bases da hermenêutica constitucional são facilmente negligenciadas, inclusive porque largamente desconhecidas, ainda que seus expoentes doutrinadores sejam os mais citados. Sem maiores constrangimentos, normas-regras passam a ser ponderadas pelos tribunais como se princípios fossem. Como sabiamente ilustram Alexandre Morais da Rosa e Rafael Tomaz de Oliveira (2013), ao melhor (ou pior) estilo "Juiz MacGyver" e seu "canivete suíço", sempre se encontra um "jeitinho" hermenêutico para moldar o caso a decidir ao talante (autoridade) do seu juízo subjetivo.

De fato, a problemática do deficit de racionalidade do modelo ponderacionista impõe a construção de uma adequada teoria de justificação racional, uma teoria da argumentação jurídica capaz de conferir os necessários padrões de correção à aplicação do Direito, a fim de assegurar o efetivo controle da atividade administrativa e os limites racionais aos casos de intervenções judiciais ${ }^{5}$. A máxima supressão, na maior medida possível, daquele deficit de racionalidade do discurso jurídico, é o ponto sensível do modelo de ponderação proporcional.

Mais do que uma teoria da justificação jurídica racional, urge a consolidação de uma cultura de justificação e correção das decisões político-legislativas, administrativas e judiciais. Sobretudo naqueles casos em que a construção legislativa de consensos e a atuação administrativa e judicial estão diretamente relacionadas à resolução de conflitos entre legítimos e contrapostos direitos e interesses com status constitucional.

Isso demandaria, no mínimo, a construção de uma robusta teoria dos direitos fundamentais ${ }^{6}$, o radical alargamento dos instrumentos de democracia ativa e participativa, a profunda republicanização do Estado e a

\footnotetext{
${ }^{5}$ Ainda que de central relevância, ultrapassa os limites do presente estudo a análise ou tentativa de reconstrução das principais teorias e modelos de argumentação jurídica construídos pela metodologia jurídica contemporânea. Nesse sentido, apenas para citar algumas propostas teóricas amplamente difundidas, pode-se destacar a tópica de Theodor Viehweg, a nova retórica de Chaïm Perelman e a teoria da justificação jurídica racional de Robert Alexy. Para análise nos próprios autores, pode-se consultar: Alexy (2001), Perelman e Olbrechts-Tyteca (1996) e Viehweg (1964).

${ }^{6}$ Sobre a rica temática dos direitos fundamentais, consultar: Novais (2007, p. 80-113) e Sarlet (2007).
} 
consolidação de uma cultura de supremacia da Constituição. Pautas que em muito superam os acanhados limites do debate meramente jurídico. Mas o início dessa hercúlea e relevante tarefa pode partir da construção de uma sólida teoria da proporcionalidade e da ponderação de interesses, com a fixação dos seus limites operativos básicos (formais e materiais).

\section{A Ponderação de Princípios e seus Limites de Aplicação: pon- deração constitucional, legislativa e judicial}

Conforme já se disse alhures ${ }^{7}$, o método da ponderação de interesses impõe a aplicação de um procedimento racional, a fim de alcançar o resultado de concretização otimizada daqueles direitos e interesses reconhecidos pela ordem normativa vigente. Trata-se de uma atividade que deve ser dimensionada com base em uma ordem hierarquizada, a partir das balizas constitucionais.

Dessa maneira, o primeiro nível de aferição da relação de conflito é sempre o sistema constitucional e sua ordem de regras e princípios positivados. Em um segundo nível de ponderação proporcional, conduz-se ao espaço da legislação infraconstitucional e de todo o arcabouço normativo, que somente pode ser aplicado após o teste de constitucionalidade e o exercício de ponderação e harmonização ao conjunto normativo constitucional.

Um dos espaços de concretização da ponderação decisória, no caso de conflitos entre interesses (públicos e privados), gravita em torno do aparato da Administração Pública e sua estrutura orgânica, na sua dinâmica e precípua atividade finalística estatal de densificação do conjunto de normas constitucionais e infraconstitucionais que compõem a ordem normativa vigente.

Por outro lado, o espaço da mais efetiva aplicação do modelo de ponderação proporcional é aquele que povoa as decisões judiciais de concretização de direitos, a partir da solução de conflitos entre direitos

${ }^{7}$ Para uma análise mais detida sobre a temática aqui recuperada, consultar: Cristóvam (2016, p. 258-271). 
e interesses contrapostos (judicialização das colisões entre interesses públicos, coletivos, sociais, privados, individuais), além do amplo espectro de medidas relacionadas ao controle de constitucionalidade das leis e dos atos normativos em geral. É no palco do debate judicial entre direitos e interesses, em especial se amparados em princípios constitucionais e infraconstitucionais, que emerge a mais efervescente aplicação do modelo ponderacionista, albergando tanto a produção legítima e racional da decisão judicial, como também toda sorte de excessos decisionistas e moralismos subjetivos usurpadores da autoridade do sistema normativo (constitucional e infraconstitucional).

Quando se debate acerca da aplicação da teoria da ponderação de interesses na solução de um suposto conflito, uma questão preliminar que deve ser observada refere-se à efetiva existência de um conflito entre direitos ou interesses a ser resolvido pela máxima (postulado) da ponderação proporcional. Isso porque antes de cogitar em ponderação de interesses, importa averiguar se há um verdadeiro conflito concreto entre direitos ou interesse, ambos de mesma estatura normativa (constitucional ou infraconstitucional).

Dessa forma, Daniel Sarmento procura oferecer uma espécie de metodologia de aplicação da ponderação de interesses, segundo a qual a primeira necessidade seria a exata identificação do real conflito entre princípios. Isso é importantíssimo, porquanto há muitos casos em que a delimitação do âmbito de abrangência de cada um dos princípios supostamente contrapostos já é suficiente para harmonizá-los, em uma espécie de diagnóstico dos "limites imanentes" daqueles direitos e interesses aparentemente em colisão. Se confirmado o conflito, com base nas situações concretas, caberia ao intérprete "[...] impor 'compreensões' recíprocas sobre os interesses protegidos pelos interesses em disputa, objetivando lograr um ponto ótimo, onde a restrição a cada interesse seja a mínima indispensável à sua convivência com o outro." (SARMENTO, 2000, p. 102).

Com efeito, a primeira pergunta a ser respondida, de forma justificada, pela decisão judicial que pretende aplicar o modelo ponderacionista é a seguinte: há, de fato, um autêntico conflito entre princípios ou interesses efetivamente contrapostos e de mesma ordem normativa? 
O alerta para a análise preliminar da real existência de uma situação de conflito entre interesses reveste-se de redobrada relevância, se considerado o fato de que, na verdade, as relações entre interesses públicos, coletivos, sociais, privados e individuais gravitam mais na dimensão da complementaridade e da harmonia do que na linha do efetivo conflito (contraposição). Com efeito, há várias situações em que a defesa ou promoção de um interesse individual acaba por resultar na concretização de um interesse coletivo, e vice-versa. Pelas linhas normativas de uma Constituição como a nacional, interesses públicos e privados muito mais convergem sob o signo de uma dialética da harmonia, do que divergem. A regra é a convergência e não o conflito (SCHIER, 2005, p. 234-235).

Por outro lado, a relação de conflito entre interesses públicos e interesses privados pode sim ser instalada a partir de determinada situação prática, a conduzir para o campo comum da máxima ou postulado da ponderação proporcional. Mas convém ressaltar que a Constituição Federal não alberga qualquer teoria de prevalência abstrata e absoluta, inclusive no caso dos direitos fundamentais. No sistema constitucional nacional não se pode cogitar de uma estática relação de hierarquia entre interesses públicos e privados, ainda que veiculados por meio de direitos fundamentais ${ }^{8}$.

Voltando ao tema central, para aqueles casos de real conflito entre interesses (públicos, coletivos, sociais, privados, individuais), o espaço comum do debate ponderacionista povoa o sistema constitucional e seu vasto conjunto normativo de princípios expressa ou implicitamente positivados, a veicular os mais variados direitos e interesses constitucionalmente assegurados.

Nota-se que no parágrafo anterior não foram acrescentadas as normas do tipo regras como pertencentes ao debate ponderacionista, o que impõe um necessário esclarecimento. Conforme consolidado pela hermenêutica contemporânea, o método de ponderação proporcional tem efetiva aplicação no caso de conflitos entre princípios constitucionais e os respectivos direitos e interesses correspondentes. Portanto, tanto como normas

\footnotetext{
${ }^{8}$ Para uma análise aprofundada sobre a questão do conflito entre interesses públicos e privados e o afastamento do princípio da supremacia do interesse público, consultar: Binenbojm (2008, p. 81-124) e Cristóvam (2015, p. 121-172) e Sarmento (2005).
} 
aplicáveis à maneira de um "tudo ou nada" (DWORKIN, 1989); ${ }^{9}$ como no sentido de normas que veiculam mandamentos definitivos (ALEXY, 1993) $;{ }^{10}$ ou, ainda, segundo o conceito de normas de conduta que estabelecem indiretamente fins, com a prescrição em maior exatidão do comportamento devido (ÁVILA, 2004), ${ }^{11}$ importa considerar que o espaço comum à ponderação proporcional não é aquele das normas-regras, mas o das normas-princípios. Esta questão dos limites operativos ao modelo de ponderação e sua necessária relação de respeito às regras constitucionais e infraconstitucionais será retomada e abordada com a devida profundidade.

No âmbito da ponderação constitucional, o legislador constituinte originário dispõe de ampla liberdade jurídica para normatizar ponderações entre bens, valores, interesses e direitos, estabelecendo ordens de prevalência. Neste quadrante, um exemplo de preferência ao interesse público pode ser encontrado no artigo $5^{\circ}$, XXV da Constituição Federal, quando prevê que "[...] no caso de iminente perigo público, a autoridade competente poderá usar de propriedade particular, assegurada ao proprietário indenização ulterior, se houver dano [...]". Por outro lado, há exemplos de prioridade aos interesses individuais, como prescreve o artigo $5^{\circ}$, $\mathrm{XI}$, ao assegurar que “[...] a casa é asilo inviolável do indivíduo, ninguém nela podendo penetrar sem consentimento do morador, salvo em caso de flagrante delito ou desastre, ou para prestar socorro, ou, durante o dia, por determinação judicial”.

Com base nos referidos exemplos, Paulo Ricardo Schier (2005) sustenta que, enquanto no caso do "eminente perigo público", a primazia é do interesse público, no caso do direito à inviolabilidade do domicílio, a Constituição tutela com clara preferência a privacidade do indivíduo, que somente poderá ser superada nos casos excepcionais de flagrante delito, desastre, prestação de socorro, ou seja, situações de interesse público. Assim, as eventuais

\footnotetext{
${ }^{9}$ Para estudos complementares, consultar: Dworkin (1989).

${ }^{10}$ Para estudos complementares, consultar: Alexy (1993).

${ }^{11}$ Para estudos complementares, consultar: Ávila (2004).
} 
[...] colisões são resolvidas previamente pelo constituinte originário, que pode optar pela prevalência dos interesses privados (como parece ser o mais usual) ou pela prevalência dos interesses públicos (como parece ser a exceção em homenagem ao princípio da legalidade e do Estado de Direito). (SCHIER, 2005, p. 235-237)

Vale ressaltar que, no caso da Constituição Federal, sumamente detalhista e abrangente nas suas prescrições normativas, há várias ocorrências de ponderações constitucionais, com restrições abstratas e apriorísticas de vários direitos e interesses, o que deve ser respeitado pelos poderes constituídos. De fato, como expressão máxima da normatividade constitucional fundante de um novo sistema jurídico-político, os limites que o poder constituinte originário conhece e reconhece são aqueles de ordem política e filosófica, mas não propriamente jurídica.

Nesse sentido, a ordem constitucional pode antever e resolver, de forma definitiva e abstrata, determinados conflitos concretos entre interesses, a partir de uma norma explícita de restrição a determinado direito ou interesse, a exemplo do que ocorre em alguns casos de "normas de eficácia contida", submetidas à própria contenção constitucional.

A contenção constitucional explícita ocorre, v.g., no conhecido exemplo da restrição ao direito de propriedade garantido pelo artigo $5^{\circ}$, XXII da Constituição Federal, que sofre clara contenção/ruptura nos casos de desapropriação por necessidade ou utilidade pública, ou por interesse social (artigo $5^{\circ}, \mathrm{XXIV}$ da $\mathrm{CF} / 88$ ), situações em que a ordem constitucional assegura a justa e prévia indenização em dinheiro, com meio de compensação proporcional pelo direito restringido.

No caso da desapropriação, a ordem constitucional foi de extrema minudência, ao prever, inclusive, situações de restrição àquela compensação proporcional da indenização em dinheiro. A partir da aplicação ponderada e até harmoniosa do já referido artigo $5^{\circ}$, XXII (direito de propriedade) com o artigo $5^{\circ}$, XXIII (a propriedade atenderá a sua função social), o sistema constitucional prevê determinados casos de penalização pelo descumprimento desta última cláusula, como ocorre na desapropriação para promoção do adequado aproveitamento do solo urbano (artigo $182, \S 4^{\circ}$, III da $\mathrm{CF} / 88$ ) e na desapropriação para fins de reforma agrária 
(artigo 184, caput da CF/88), em que o pagamento da indenização ocorre por meio de títulos da dívida pública e títulos da dívida agrária, respectivamente.

Já foi que o artigo $5^{\circ}$, em seus incisos XXII e XXIII, representa situações de harmonização entre interesses públicos (função social da propriedade) e privados (propriedade), porque não se excluem e sim se complementam. De acordo com Schier (2005, p. 237), na referida situação há uma autêntica

[...] síntese dialética: a propriedade nem se presta apenas para satisfazer os interesses exclusivos do proprietário e nem tampouco justifica um sentido de coletivização ou funcionalização absoluta de sua utilização.

Há outra situação em que o próprio legislador constituinte originário previu verdadeiro caso de confisco expropriatório, sem qualquer direito à indenização, para aquelas situações de glebas em que forem localizadas culturas ilegais de plantas psicotrópicas, que passam a ser destinadas ao assentamento de colonos, para o cultivo de produtos alimentícios e medicamentosos (art. 243, caput da CF/88). Aqui, em uma radical ponderação de interesses, ante a gravidade da conduta antijurídica e lesiva aos interesses sociais e coletivos, o legislador constituinte originário - único legitimado para uma medida dessa gravidade - decidiu por suprimir integralmente o direito à propriedade, sem qualquer medida compensatória. Medidas extremas como essa, assim aniquiladoras em abstrato de um direito ou interesse, somente são admissíveis pela via da ponderação constitucional, fruto de decisão política do legislador constituinte.

Situações normativas como as do regime constitucional da desapropriação deixam uma margem reduzida para os âmbitos de ponderação legislativa, administrativa e judicial. No caso da ponderação legislativa, a margem fica limitada a um universo mais restrito de regulamentação daquelas escolhas constitucionais. Caberá ao legislador regulamentar, por exemplo, os casos de desapropriação por necessidade ou utilidade pública, ou interesse social, definir os procedimentos administrativo e judicial, os parâmetros de concretização da indenização justa, prévia e em dinheiro 
(Decreto-Lei n. 3.365, de 21 de junho de 1941 e Lei n. 4.132, de 10 de setembro de 1962, ambos recepcionados pela $\mathrm{CF} / 88$ ).

Nessa circunstância, a ponderação administrativa estaria relacionada ao nível mais abrangente de concretude, comum à atividade finalística própria da Administração Pública, seus órgãos e agentes, na definição dos casos concretos de necessidade ou utilidade pública, ou interesse social, ou seja, os termos e limites práticos da indenização justa, prévia e em dinheiro, tudo submetido e subsumido aos parâmetros constitucionais e infraconstitucionais. Por sua vez, à ponderação judicial, como espaço de revisão da atividade concreta da Administração Pública, remanesceria a instância última de solução dos conflitos decorrentes da atividade concreta de desapropriação administrativa, solvendo quaisquer inadequadas atuações das duas instâncias ponderacionistas anteriores, a fim de assegurar a fiel e otimizada observância da ordem constitucional.

Numerosos e variados seriam os outros casos de possíveis conflitos de interesses, mas sem uma apriorística ponderação constitucional definitiva, a partir da restrição abstrata de um dos interesses em favor de outros. Assim, pode-se fazer referência àquelas situações em que o próprio legislador constituinte expressamente remete ao legislador infraconstitucional a atribuição de ponderação restritiva e regulamentadora daquele direito ou interesse. Esse é o caso do artigo $5^{\circ}$, XII da Constituição Federal, quando prescreve ser "inviolável o sigilo da correspondência e das comunicações telegráficas, de dados e das comunicações telefônicas, salvo, no último caso, por ordem judicial, nas hipóteses e na forma que a lei estabelecer para fins de investigação criminal ou instrução processual penal". No mesmo sentido, pode-se referir ao artigo $5^{\circ}$, XIII, que assegura ser "livre o exercício de qualquer trabalho, ofício ou profissão, atendidas as qualificações profissionais que a lei estabelecer".

Há também diversos outros casos práticos, que povoam os debates diários das atividades administrativas e das decisões judiciais, aqueles em que não existe ponderação constitucional definitiva nem expressa remissão à ponderação legislativa de regulamentação. Tais casos ensejam situações concretas de juízos de ponderação um pouco mais alargados, porquanto não subsumidos a uma estreita moldura normativa preestabe- 
lecida. Ainda assim, para todos os casos a solução pela prevalência de um dos interesses em conflito passará pela racional aplicação do método de ponderação proporcional, levando-se em conta as circunstâncias fáticas e jurídicas reveladoras da relação de precedência. Em nenhuma hipótese, admite-se a ponderação proporcional como um exercício de revelação intuitiva de uma autoridade. Todos os juízos de ponderação somente serão legítimos se puderem remontar à ordem normativa constitucional e infraconstitucional vigente.

Mas ainda são necessárias outras disposições limitativas e impositivas de obrigações insuprimíveis ao processo aplicativo da teoria da ponderação proporcional de interesses, sem as quais o referido modelo acaba por se tornar indefeso, refém de inadequados subjetivismos, insubsistentes decisionismos e até uma perigosa abertura a toda sorte de intuicionismos morais ilegitimamente fundados na autoridade daquele que conduz o processo ponderativo.

Nesse quadrante, com elevada consistência teórica e preocupação prática, depois de estabelecer um sólido juízo crítico acerca do infundado e insubsistente desprestígio operativo e normativo a que vêm sendo relegadas as regras jurídicas, Ávila (2009, p. 3-17) apresenta três diretrizes fundamentais à construção de um modelo de ponderação intersubjetivamente controlável e compatível com o sistema de separação de poderes, que podem ser assim descritas:

1. O respeito à força normativa das regras constitucionais imediatamente aplicáveis ao caso.

2. O respeito à força normativa das regras infraconstitucionais, se editadas nos limites da ordem constitucional.

3. O respeito a padrões mínimos de racionalidade e justificação no processo de ponderação proporcional.

Sobre a primeira diretriz fundamental ao modelo de ponderação proporcional, importa ressaltar que o processo de ponderação horizontal entre princípios constitucionais somente poderá ser estabelecido se inexistente uma regra constitucional impositiva da solução normativa para o caso concreto. A existência de uma regra constitucional imediatamente 
aplicável representa uma ponderação constitucional com pretensão jurídica de definitividade, que não pode ser simplesmente ignorada pela autoridade legitimada para aplicar a norma. Não se pode negligenciar a regra constitucional, sob a singela justificação de que não representa o meio mais adequado para a otimização dos princípios constitucionais ou, ainda, que todas as regras somente ganham vida operativa a partir da ponderação entre os princípios constitucionais colidentes. Isto não exclui, por outro lado, a excepcional possibilidade de o aplicador da norma, [...] dentro dos limites semânticos da regra e obedecendo às suas funções, interpretar a regra conforme os princípios constitucionais axiologicamente subjacentes ou a sua finalidade (ÁVILA, 2009, p. 10-11).

No mesmo sentido, se ausente uma regra constitucional imediatamente aplicável, deve-se perquirir acerca da existência de uma norma constitucional que estabeleça "a atribuição, o exercício ou a delimitação de uma competência" ao Parlamento para legislar sobre determinadas matérias. Presente a referida regra atributiva de competência legislativa, se cumprida a mediação legislativa dentro dos limites constitucionais por meio de regras jurídicas parametrizadas com a Constituição, a autoridade administrativa ou judicial deve conduzir suas decisões a partir daqueles comandos normativos infraconstitucionais. Isto não significa, por certo, negligenciar a inegável possibilidade de interpretação de regras jurídicas a partir dos princípios constitucionais, com a adoção do sentido que melhor se ajuste à ordem constitucional, a partir da justificada equalização restritiva ou ampliativa da regra normativa para o otimizado alcance da sua finalidade, havendo até a possibilidade do seu afastamento, em casos de inegável condição de extraordinariedade. Mas nunca simplesmente desconsiderar a regra jurídica, a partir de um juízo obscuro e ilegítimo de preferências subjetivas (ÁVILA, 2009, p. 11).

A terceira diretriz fundamental, também absolutamente essencial à pretensão de racionalidade do paradigma da ponderação proporcional, refere-se às exigências de justificação das decisões ponderativas. Sobre a questão, se ausente uma regra constitucional ou infraconstitucional imediatamente aplicável ao caso, Ávila (2009) sustenta a necessária consideração de três momentos essenciais ao processo ponderativo, que são a 
indicação dos princípios objeto de ponderação (pré-ponderação), a ponderação em si e a sua fundamentação.

Para essa fundamentação, emergem cinco elementos basilares para a argumentação ponderativa, segundo Ávila (2009, p. 11-12):

1. As razões de justificação da preferência ponderativa de determinado(s) princípio(s) em detrimento de outro(s).

2. Os critérios usados para a definição do peso e da prevalência daquele(s) determinado(s) princípio(s) em detrimento do(s) outro(s), bem como a relação entre esses critérios.

3. O "procedimento e o método que serviram de avaliação e comprovação do grau de promoção de um princípio e o grau de restrição de outro".

4. A "comensurabilidade dos princípios cotejados e o método utilizado para fundamentar essa comparabilidade".

5. O conjunto de fatos relacionados ao caso que foram considerados relevantes para a ponderação e "com base em que critérios eles foram juridicamente avaliados".

Todas essas obrigações de justificação das decisões ponderativas acabam por oferecem uma relevante contribuição para a formação de um conjunto mínimo de limites ao decisionismo judicial, capazes de assegurar razoáveis padrões de racionalidade na aplicação judicial da teoria da ponderação de princípios.

Isso pode ser alcançado a partir do efetivo respeito às regras constitucionais e infraconstitucionais veiculadoras de decisões político-legislativas da autoridade normativa legítima (normas imediatamente aplicáveis ao caso concreto), que somente podem ser relativizadas em casos de extremadas peculiaridades, mesmo assim somente com base em processos de interpretação capazes de racionalmente justificar a decisão judicial, afastado qualquer recurso a juízos subjetivos. Se os últimos anos foram de intensa defesa da força normativa dos princípios constitucionais, o discurso jurídico contemporâneo parece carecer atualmente de um movimento de recuperação da força normativa das regras jurídicas, como mo- 
dais normativos definitivos e impositivos, de plena observância inclusive pelo Poder Judiciário.

No mesmo sentido, a imposição de parâmetros formais e materiais de justificação da decisão ponderativa submete o julgador a um considerável ônus argumentativo, trazendo em potência efetivas condições de restrição ao uso do modelo ponderacionismo como fator de proliferação do decisionismo e do moralismo judicial. Não que a partir desses parâmetros seja possível defender uma ampla e insuperável blindagem ao subjetivismo judicial, até porque os excessos e desvios do modelo ponderacionista parecem decorrer muito mais da prática desavisada das decisões judiciais (pouco afetas ao dever de justificação racional) do que propriamente de suas alegadas insubsistências teóricas.

\section{Conclusão}

Não se pode negar que a aplicação da teoria da ponderação de interesses não é algo assim tão simples. Sobretudo em uma sociedade como a brasileira, ainda fundada em instituições democráticas de enorme fragilidade e baixa legitimação no seio da população. E aqui não se está referindo-se apenas ao Legislativo e ao Executivo, comumente marginalizados e até demonizados por "oposicionismos de ocasião" e por setores da mídia nacional, como se fossem os únicos redutos de todas as chagas da corrupção e do patrimonialismo estatal. O deficit de legitimação alcança, sem maiores discriminações, todas as demais instituições: o Poder Judiciário, o Ministério Público, os Tribunais de Contas, as Instituições Públicas Financeiras etc.

$\mathrm{Na}$ verdade, essa crise de legitimação parece ser mais profunda, atacando o próprio Estado por completo. A sociedade (povo) vê o Estado como o "outro": umas vezes até como "provedor", outras tantas como verdadeiro "inimigo". Mas quase nunca como aquela síntese das aspirações coletivas e supraindividuais. Muito disso, vale reconhecer, parece ser parte de uma realidade cirurgicamente orquestrada por alguns "donos 
do poder", ${ }^{12}$ por uma mídia de discursos monolíticos e monopolizadores da verdade, por vezes condutora da frágil e instável "opinião pública", por caminhos de verdades fabricadas, postas a serviço de algumas rarefeitas e oportunistas noções de interesse público, sob as quais mimetizam escusos e egoísticos interesses de grupos políticos e econômicos.

Vale ressaltar que, quando se faz referência a uma mídia de discursos monopolizadores da verdade, não se pretende aqui o recurso retórico a frases de efeito ou algo do gênero. De fato, não se pode descuidar que no Brasil as normas e as práticas (reiteradas e notórias) convergem para a construção de verdadeiros "monopólios da informação", permitindo-se que um mesmo grupo empresarial explore concessões de rádio, jornal e televisão (imprensa falada, escrita e televisionada), do que decorre uma perigosa concentração de poder sociopolítico nas mãos de determinados setores da imprensa, fator que pode resultar em efetivo entrave para o fortalecimento da democracia.

Esse traço de fragilidade das instituições democráticas vem acompanhado, ainda, pela crônica ausência de uma radical cultura de supremacia da Constituição, a exigir uma construção do discurso jurídico sobre as sólidas bases da hermenêutica constitucional contemporânea. No Brasil, não são raros os discursos que justificam o desprestígio e o descumprimento a normas constitucionais assecuratórias de direitos, sob o pretexto de vedações e limitações infraconstitucionais. Por vezes, gestores públicos deixam de cumprir a Constituição para fazer valer a Lei de Responsabilidade Fiscal (Lei Complementar n. 101, de 04 de maio de 2000). É notório o "calote institucionalizado" de incontáveis Entes Federados (Estados e Municípios), que simplesmente negligenciam o pagamento de dívidas judicialmente reconhecidas, sem sequer obedecer aos limites temporais daquele já famigerado sistema de precatórios. Com uma surpreendente desfaçatez, nega-se autoridade e força vinculativa às decisões judiciais e ao próprio instituto da coisa julgada.

Em síntese, num cenário assim desenhado, a construção do modelo de ponderação de interesses carece de um afirmativo refinamento teórico,

${ }^{12}$ Alusão à expressão difundida a partir da obra do jurista e historiador Raymundo Faoro. Nesse sentido, consultar: Faoro (1977). 
explicitando-se os seus limites e procedimentos, como forma assecuratória do alcance das suas finalidades últimas, a supremacia da Constituição e a promoção e defesa dos direitos fundamentais. O resultado da ponderação de interesses deve ser a concretização daquele modelo material de justiça constitucional sobre o qual se funda o Estado constitucional de direito. E não o signo da incerteza política, da insegurança jurídica e do primado da autoridade (daquele que legisla, daquele que administra ou daquele que julga). A única autoridade legítima é a vontade soberana do povo normatizada na Constituição. O que parece ser, na atual encruzilhada do discurso jurídico contemporâneo, o bom combate a ser combatido!

\section{Referências}

ALEXY, Robert. Teoria da argumentação jurídica: a teoria do discurso racional como teoria da justificação jurídica. Tradução de Zilda Hutchinson Schild Silva. São Paulo: Landy, 2001.

. Teoría de los derechos fundamentales. Traducción de Ernesto Garzón Valdés. Madrid: Centro de Estudios Constitucionales, 1993. ÁVILA, Humberto. Teoria dos princípios: da definição à aplicação dos princípios jurídicos. 4. ed. São Paulo: Malheiros, 2004.

. Neoconstitucionalismo: entre a "ciência do Direito" e o "Direito da ciência". Revista Eletrônica de Direito do Estado (REDE), Salvador, n. 17, p. 1-19, jan.-mar. 2009. Disponível em: $<$ http://www.direitodoestado.com/revista/REDE-17-JANEIRO-2009HUMBERTO\%20AVILA.pdf>. Acesso em: 23 jan. 2017.

BINENBOJM, Gustavo. Uma teoria do Direito Administrativo: direitos fundamentais, democracia e constitucionalização. 2. ed. São Paulo: Renovar, 2008.

BRAGA, Valeschka e Silva. Princípios da proporcionalidade \& da razoabilidade. 2. ed. 1. tir. Curituba: Juruá, 2009.

CARBONEL, Miguel (Coord.). Teoría del neoconstitucionalismo: ensaios escogidos. Madrid: trotta, 2007. 
CARBONELL, Miguel; SALAZAR, Pedro (Coord.). Garantismo: estudios sobre el pensamiento jurídico de Luigi Ferrajoli. Madrid: Trotta, 2005.

\section{CRISTÓVAM, José Sérgio da Silva. Administração Pública}

democrática e supremacia do interesse público: novo regime jurídicoadministrativo e seus princípios constitucionais estruturantes. Curitiba: Juruá, 2015.

. Princípios constitucionais: razoabilidade, proporcionalidade e argumentação jurídica. 2. ed. Curitiba: Juruá, 2016.

DWORKIN, Ronald. Los derechos en serio. Traducción de Marta Guastavino. 2. ed. Barcelona: Ariel Derecho, 1989.

FAORO, Raymundo. Os donos do poder: formação do patronato político brasileiro. v. I, 4. ed. Porto Alegre: Globo, 1977.

FERRAJOLI, Luigi. Constitucionalismo principialista e constitucionalismo garantista. In: FERRAJOLI, Luigi; STRECK, Lenio Luiz; TRINDADE, André Karam (Org.). Garantismo, hermenêutica e (neo)constitucionalismo: um debate com Luigi Ferrajoli. Porto Alegre: Livraria do Advogado, 2012. p. 13-56.

. Garantismo: una discusión sobre derecho y democracia.

Madrid: Trotta, 2006.

NOVAIS, Jorge Reis. Direitos como trunfos contra a maioria: sentido e alcance da vocação contramajoritária dos direitos fundamentais do Estado de direito democrático. In: CLÈVE, Clèmerson Merlin; SARLET, Ingo Wolfgang; PAGLIARINI, Alexandre Coutinho (Org.). Direitos humanos e democracia. Rio de Janeiro: Forense, 2007. p. 80-113. PERELMAN, Chaïm; OLBRECHTS-TYTECA, Lucie. Tratado da argumentação: a nova retórica. Tradução de Maria Ermantina Galvão G. Pereira. São Paulo: Martins Fontes, 1996.

ROSA, Alexandre Morais da; OLIVEIRA, Rafael Tomaz de. Complexo de MacGyver e os modelos de juízes (episódio 1). Revista Eletrônica Consultor Jurídico, São Paulo, nov. 2013. Disponível em: $<$ http://www. 
conjur.com.br/2013-nov-02/diario-classe-complexo-macgyver-modelosjuiz-episodio $>$. Acesso em: 16 jan. 2017.

SARLET, Ingo Wolfgang. A eficácia dos direitos fundamentais. 9. ed. Porto Alegre: Livraria do Advogado, 2007.

SARMENTO, Daniel (Org.). Interesses públicos versus interesses privados: desconstruindo o princípio da supremacia do interesse público. Rio de Janeiro: Lúmen Júris, 2005.

. O neoconstitucionalismo no Brasil: riscos e possibilidades. In:___. Filosofia e teoria constitucional contemporânea. Rio de Janeiro: Lumen Juris, 2009. p. 113-146.

. A ponderação de interesses na Constituição Federal. Rio de Janeiro: Lumen Juris, 2000.

SCHIER, Paulo Ricardo. Ensaio sobre a supremacia do interesse público sobre o privado e o regime jurídico dos direitos fundamentais. In: SARMENTO, Daniel (Org.). Interesses públicos versus interesses privados: desconstruindo o princípio da supremacia do interesse público. Rio de Janeiro: Lúmen Júris, 2005. p. 217-242.

STRECK, Lenio Luiz. O pan-principiologismo e o sorriso do lagarto. Revista Eletrônica Consultor Jurídico, São Paulo, mar. 2012. Disponível em: <http://www.conjur.com.br/2012-mar-22/sensoincomum-pan-principiologismo-sorriso-lagarto $>$. Acesso em: 16 jan. 2017.

SUNDFELD, Carlos Ari. Direito Administrativos para céticos. São Paulo: Malheiros, 2012.

VIEHWEG, Theodor. Tópica y jurisprudencia. Traducción de Luis Díez-Picazo Ponce de Leon. Madrid: Taurus, 1964.

José Sérgio da Silva Cristóvam é professor adjunto de Direito Administrativo da Universidade Federal de Santa Catarina, doutor em Direito Administrativo pela mesma instituição (com estágio de Doutoramento Sanduíche na Universidade 
de Lisboa - Portugal), mestre em Direito Constitucional também pela UFSC, especialista em Direito Administrativo pelo Complexo de Ensino Superior de Santa Catarina, membro fundador e presidente do Instituto Catarinense de Direito Público (ICDP), membro fundador do Instituto de Direito Administrativo de Santa Catarina (IDASC) e da Academia Catarinense de Direito Eleitoral (ACADE), membro efetivo do Instituto dos Advogados de Santa Catarina (IASC), conselheiro estadual da $\mathrm{OAB} / \mathrm{SC}$, presidente da Comissão de Acesso à Justiça da $\mathrm{OAB} / \mathrm{SC}$ e membro da Comissão de Direito Constitucional e da Comissão da Moralidade Pública da $\mathrm{OAB} / \mathrm{SC}$.

E-mail: jscristovam@gmail.com.

Endereço profissional: Universidade Federal de Santa Catarina, Centro de Ciências Jurídicas, Campus Universitário, Trindade, Florianópolis, SC, Brasil 88040-900. 
